\title{
Penerapan Media Sempoa untuk Meningkatkan Kedisiplinan, Ketelitian, dan Tanggung Jawab Mahasiswa Kelas Inovatif Matematika
}

\author{
Andri Anugrahana
}

(C) 2020 JEMS (Jurnal Edukasi Matematika dan Sains)

This is an open access article under the CC-BY-SA license (https://creativecommons.org/licenses/bysa/4.0/) ISSN 2337-9049 (print), ISSN 2502-4671 (online)

\begin{abstract}
Abstrak:
Penelitian ini bertujuan untuk mengetahui penerapan Media Sempoa dalam pembelajaran matematika dan juga meningkatkan kedisiplinan, ketelitian dan tanggung jawab mahasiswa setelah mengikuti kegiatan pembelajaran matematika. Rancangan penelitian yang digunakan adalah tidakan kelas dengan jumlah sampel 31 mahasiswa kelas Inovatif matematika di PGSD Universitas Sanata Dharma. Rancangan materi penelitian adalah penjumlahan dan juga pengurangan matematika dengan media sempoa. Instrumen yang digunakan untuk mengukur kedisiplinan, ketelitian dan juga tanggung jawab adalah dengan lembar observasi dan juga wawancara. Hasil penelitian menunjukkan bahwa media sempoa dalam pembelajaran matematika dapat meningkatan kedisiplinan. Ketelitian, dan tanggung jawab mahasiswa PGSD kelas inovatif matematika sebesar $100 \%$.
\end{abstract}

Kata Kunci : Media Sempoa, Kedisiplinan, Ketelitian, Tanggung Jawab

\begin{abstract}
:
This study aims to determine the application of Abacus Media in mathematics learning and also improve student discipline, accuracy and responsibility after participating in mathematics learning activities. The study design used was classroom action research with a sample of 31 students of Innovative mathematics classes at PGSD Sanata Dharma University. The design of the research material is the addition and reduction of mathematics with abacus media. The instrument used to measure discipline, accuracy and also responsibility is the observation sheet and also the interview. The results showed that abacus media in learning mathematics can increase discipline. The accuracy and responsibility of PGSD students in innovative mathematics classes is $100 \%$.
\end{abstract}

Keywords : Abacus Media, Discipline, Accuracy, Responsibility

\section{Pendahuluan}

Paradigma pendidikan yang sesuai dengan tantangan zaman pada saat ini adalah pendidikan yang mampu menyiapkan manusia abad ke-21. Perubahan paradikma dalam proses pembelajaran yaitu paradigma mengajar menjadi belajar atau pembelajaran yang awalnya berpusat dari guru menjadi pembelajaran yang berpusat pada siswa. Pembelajaran yang berpusat pada siswa dimana siswa dilibatkan dalam pembelajaran dan guru hanya berperan sebagai fasilitator. 
Siswa lebih banyak aktif dan terlibat dalam pembelajaran. Hal ini sejalan dengan UU sisdiknas no 20 tahun 2013 bab 1 pasal 1 yang menjelaskan bahwa Pendidikan adalah usaha sadar dan terencana untuk mewujudkan suasana belajar dan proses pembelajaran agar peserta didik secara aktif mengembangkan potensi dirinya untuk memiliki kekuatan spiritual keagamaan, pengendalian diri, kepribadian, kecerdasan, akhlak mulia, serta keterampilan yang diperlukan dirinya, masyarakat, bangsa dan negara. Oleh karena itu, guru perlu menciptakan dan memfasilitasi peserta didik untuk aktif mengembangkan potensi diri.

Pembelajaran matematika adalah salah satu pembelajaran yang ada di sekolah maupun yang ada di Universitas khususnya prodi PGSD (Pendidikan khususnya calon guru SD perlu mendapatkan bekal matematika dasar. Hal ini sejalan juga dengan pendapat Susanto bahwa Pembelajaran Matematika adalah suatu proses belajar mengajar yang dibangun oleh guru untuk mengembangkan kreativitas berfikir peserta didik yang dapat meningkatkan kemampuan mengkontruksi pengetahuan baru sebagai upaya meningkatkan penguasaan yang baik terhadap materi matematika. Pembelajaran Matematika merupakan salah satu mata pelajaran yang bertujuan untuk mengembangkan kemampuan-kemampuan kognitif, psikomotor, dan afektif siswa dalam bermatematika (doing mathematics). Pendapat ini menjelaskan bahwa matematika sebagai salah satu mata kuliah yang dapat membantu peserta didik dalam mengembangkan diri baik dari aspek kognitif ataupun afektif. Oleh karena itu guru maupun calon guru sekolah dasar perlu memiliki penguasaan matematika yang baik dan juga memiliki strategi yang sesuai sehingga tujuan pembelajaran yang direncanakan tercapai. Menurut Suyadi pembelajaran matematika tidak lagi mengutamakan pada penyerapan melalui pencapaian informasi, tetapi lebih mengutamakan pada pengembangan kemampuan dan pemrosesan informasi. Pembelajaran ini lebih banyak menekankan pada aktivitas siswa dalam bentuk latihan, tugas dan juga diskusi kelompok. Dalam kegiatan latihan maupun diskusi siswa dilatih umtuk memahami masalah, bernalar dan juga memecahkan masalah. Upaya yang perlu dilakukan pada calon guru salah satunya adalah pada mata kuliah pembelajaran inovatif matematika adalah perubahan cara mengajar mulai dari konvensional sampai pada pembelajaran ke arah yang lebih inovatif.

Anneahira mengatakan bahwa dalam dunia pendidikan kedisiplinan merupakan harga mati yang harus dibayar siswa. pengaruh displin terhadap prestasi belajar sangatlah besar sehingga perlu ditanamkan sikap disiplin dalam diri peserta didik sedini mungkin (Lomu \& Widodo, 2018: 748). Hal ini sejalan dengan pendapat Marsudi bahwa pembelajaran Matematika tidak dapat lepas dari pembelajaran karakter. Pembelajaran karakter (disiplin dan motivasi) di sekolah berperan guna peningkatan prestasi. Siswa yang belajar berhitung hendaknya bukan sekedar belajar secara mekanistik menerapkan kalkulasi angka dan bangun, tetapi mengartikan informasi yang diperoleh dari kalkulasi tersebut. Oleh karena itu konstektualisasi matematika menjadi sangat penting agar siswa mengerti makna dari apa yang dipelajari dalam kehidupan di rumah (Prasasty, 2017: 67). Kedisiplinan sebagai alat pendidikan diterapkan dalam rangka proses pembentukan, pembinaan dan pengembangan sikap serta tingkah laku yang baik. Sikap dan tingkah laku yang baik tersebut dapat berupa ijin, berbudi pekerti luhur, patuh, hormat, tenggang rasa, dan berdisiplin. Tujuan disiplin adalah mengarahkan anak agar mereka belajar mengenai hal-hal baik yang merupakan persiapan bagi masa dewasa, saat mereka sangat bergantung kepada disiplin diri (Elly, 2003: 47). Hasil obervasi menyebutkan mahasiswa terlambat lebih dari 15 menit, Alasan yang biasanya diberikan mahasiswa adalah ban embos, atau kendaraan rusak, jalanan macet. Alasan-alasan seperti itu sebenarnya masih bisa diatasi dengan baik. 
Menurut Goldberg, Ketelitian (Conscientiousness) merupakan karakteristik kepribadian yang digunakan untuk mengidentifikasi derajat individu dari organisasi. (dalam Dayanti, 2014). Asal kata "Ketelitian" yaitu dari kata dasar teliti. Kamus Besar Bahasa Indonesia Kontemporer menjelaskan arti kata teliti adalah cermat, seksama, hatihati. Sedangkan arti kata ketelitian adalah keseksamaan atau kecermatan. Dayanti (2014:61) menjelaskan ketelitian (Conscientiousness) adalah salah satu Trait kepribadian dari The big five personality yang merupakan aspek kecenderungan emosional, kognitif, dan tingkah laku, bersifat menetap dan ditampilkan individu sebagai respon terhadap berbagai situasi lingkungan. Ketidakdisiplinan disiplinan mahasiswa nampak dari cara mahasiswa mengerjakan soal-soal khususnya matematika. Masih ditemukan mahasiswa mengerjakan soal dengan tidak lengkap seperti menjawab tidak menggunakan cara dan hanya menjawab jawabannya saja. Contoh lain bentuk ketidaktelitian mahasiswa adalah mahasiswa tidak menuliskan nama dan nim dalam lembar kerja ataupun lembar tugas.

Menurut Clemes dan Bean untuk dapat memenuhi tanggung jawab, anak harus punya kemampuan melakukan tugas atau pekerjaan. Anak perlu memiliki keterampilan untuk menyelesaikan tugas dan sadar terhadap resiko jika pekerjaan tidak dikerjakan atau memberikan hasil kerja yang rendah. Anak yang belajar bertanggung jawab akan meningkatkan rasa untuk mampu melakukan sesuatu. Anak yang belajar bertanggung jawab akan membuat keputusan yang lebih baik. (Apriani, 2015) Hasil observasi pada kelas matematika inovasi menyebutkan bahwa mahasiswa masih kurang bertanggung jawab terhadaap dirinya sendiri. Misalnya tugas, ada mahasiswa yang hanya titip tanda tangan. Hasil wawanacara pribadi pada salah satu mahasiswa menyebutkan bahwa "ada juga yang mangkir bu, disuruh mengerjakan tugas kelompok banyak alasannya. Terus nannti minta namanya ditulis". Hasil wawancara tidak hanya itu saja, masih ditemukan mahasiswa yang terlambat dalam mengikuti perkuliahan. Hal ini menunjukkan kurangdisiplinnya mahasiswa dalam mengikuti perkuliahan. Bahkan hasil wawancara lebih lanjut menyebutkan karena keterpaksaan dalam memilih jurusan maka mahasiswa kurang bertanggung jawab dan mengikuti perkuliahan hanya formalitas saja. Alasan lain juga menyebutkan memilih prodi calon guru karena tuntutan dari orang tua atau karena keinginan dari orang tua. Hal ini menjadi alasan klasik mahasiswa, dengan begitu mahasiswa dapat memiliki alasan mengapa prestasi dan semangatnya tidak baik.

Media sempoa sebagai salah satu alternatif dalam menyelesaikan masalah matematika konsep berhitung. Hal ini sejalan dengan penelitian Nurhayati (2015) bahwa media mampu meningkatkan pemahaman konsep mahasiswa. Dengan menggunakan sempoa mahasiswa diharapkan mampu berhitung dengan cepat. Tetapi dalam penelitian ini, tidak hanya kemampuan berhitung saja yang dimiliki mahasiswa tetapi aspek afektif yaitu kedisiplinan, ketelitian dan juga tanggung jawab. Media sempoa mampu membantu mahasiswa sekaligus belajar menjadi lebih disiplin, teliti dan juga tanggung jawab.

Oleh karena itu, penulis memilih sempoa dalam pembelajaran matematika kelas inovatif. Menurut Ayi dan Sapriani (2015: 48), sempoa adalah sebuah alat kuno yang dipakai untuk berhitung yang dibuat dari rangka kayu dengan sederetan poros yang berisi manik-manik yang bisa digeser-geserkan. Berikut adalah bentuk dan bagian dari sempoa. Berikut adalah gambar Sempoa. Sempoa adalah alat kuno untuk berhitung yang dibuat dari rangka kayu dengan sederetan poros yang berisikan manik-manik yang bisa digeser ke kiri dan kekanan. (Ronalis, 2015). Media sempoa menjadi salah satu solusi yang dilakukan peneliti untuk meningkatkan tanggung jawab, kedisiplinan dan ketelitian dari mahasiswa. Jika dikaji lebih dalam banyak halhal pendidikan non akademi yang dapat ditanamkan dalam sempoa. 


\section{Metode}

Penelitian ini menggunakan jenis penelitian tindakan kelas yang bertujuan memperbaiki atau meningkatkan mutu kegiatan pembelajaran. Ada empat rankaian kegiatan yang dilakukan secara berulang: Perencanaan (planing), Tindakan (action), Pengamatan (observation), dan Refleksi (reflection). Subjek pemberi tindakan adalah mahasiswa PGSD kelas Inovatif. Data dikumpulkan dengan menggunakan lembar observasi pada aspek kedisiplinan, ketelitian dan tanggung jawab. Lembar observasi dosen dan mahasiswa digunakan pada saat proses pembelajaran berlangsung. Teknik pengumpulan data yang digunakan dalam penelitian ini adalah 1) observasi tentang segala aktivitas dosen dan mahasiswa selama kegiatan pembelajaran, yang dilakukan oleh observer, dan 2) wawancara. Data observasi terhadap aktivitas mahasiswa pada pembelajaran dianalisis dengan menggunakan rata-rata, yang kemudian dikategorikan dalam kriteria sangat baik, baik, cukup dan kurang.

\section{Hasil dan Pembahasan}

Bentuk kedisiplinan dalam menggunakan sempoa adalah pertama kedisiplinan dalam posisi duduk, dimana mahasiswa harus duduk dengan posisi yang benar. Mahasiswa menggunakan kursi dan juga meja yang benar untuk duduk dengan benar yaitu duduk tegap dan tidak menunduk ataupun bersandar. Kedisiplinan kedua adalah mahasiswa disiplin dengan tidak menggunakan penghapus dan jika ada kesalahan dalam mengerjakan langsung dicoret dan ada tempat untuk memperbaiki kesalahan. Kedisiplinan ketiga adalah menggunakan pensil dengan benar, benar dalaartinya pensil yang digunakan tidak terlalu panjang dan pendek. Tidak hanya itu saja cara memegang pensil juga harus benar yaitu dijepit dengan menggunakan empat jari kecuali jari jempol saat menggunakan sempoa. Kedisiplian keempat adalah posisi tangan saat menggunakan sempoa yaitu tangan tidak boleh bersadar di meja dan tangan kiri mencapit sempoa dan tangan kanan memegang pensil. Apabila mahasiswa tidak disiplin posisi tangan maka akan mempengaruhi perhitungan dengan media sempoa. Hasil observasi tingkat kedisiplinan sangat disiplin 22,5\%, disiplin 74,2\%, cukup disiplin 3,3\%. kurang disiplin 0\%, sangat kurang disiplin $0 \%$. Untuk kriteria keberhasilan adalah mulai dari cukup disiplin sampai pada disiplin sehingga ketuntasan aspek disiplin mencapai $100 \%$ (dengan kriteria cukup baik, baik dan sangat baik) tercapai.

Ketelitian yang muncul dalam menggunakan sempoa adalah pertama adanya ketelitian dalam menggerjakan tugas dan ketelitian dalam membaca petunjuk ataupun pedoman dalam penggunaan sempoa. Mahasiswa yang tidak membaca pedoman sempoa dengan baik akan kesulitan memahami sempoa. Ketelitian kedua adalah ketelitian dalam menggunakan sempoa, dengan menaikan dan menurunkan manik sempoa. Ketepatan yang dilakukan mahasiswa menunjukkan ketelitiannya dalam menggunakan sempoa. Ketelitian ketiga adalah mahasiswa dapat membedakan strategi dalam penggunaan sempoa antara tiang satuan, tiang puluhan, tiang ratusan dan seterusnya. Ketelitian keempat adalah ketelitian dalam mengoperasikan bilangan dengan strategi "teman besar" dan "teman kecil". Strategi "teman besar" dan "teman . kecil" adalah strategi yang ada di sempoaHasil observasi tingkat ketelitian dalam penggunaan media sempoa menunjukkan bahwa sangat teliti $19,3 \%$, teliti $77,4 \%$, cukup teliti 3,3\%, kurang teliti $0 \%$, sangat kurang teliti $0 \%$. Sehingga ketuntasan seluruhnya 100\% (dengan kriteria cukup baik, baik dan sangat baik) tercapai. 
Tanggung jawab yang muncul dalam penggunaan sempoa adalah pertama tanggung jawab dalam membawa sempoa dan pensil. Mahasiswa wajib membawa media tersebut karena mahasiswa belum masuk ke tahap bayangan. Tanggung jawab kedua adalah mengerjakan semua tugas ataupun latihan yang ada dalam modul sempoa, selanjutnya menggumpulkan tugas yang diberikan. Tanggung jawab ketiga adalah mengumpulkan refleksi kegiatan penggunaan sempoa. Hasil Dengan demikian total ketuntasan aspek tanggung jawab 100\% (dengan kriteria cukup baik, baik dan sangat baik). Penerapan Media Sempoa mampu meningkatkan kedisiplinan, ketelitian dan tanggung jawab mahasiswa.

Media sempoa dalam pembelajaran matematika dapat meningkatan kedisiplinan. Ketelitian, dan tanggung jawab mahasiswa PGSD kelas Matematika Inovatif sebesar 100\% dengan tingkat kedisiplinan sangat disiplin 22,5\%, Disiplin 74,2\%, Cukup disiplin 3,3\%. Kurang disiplin $0 \%$, Sangat kurang disiplin $0 \%$. Tingkat ketelitian dalam penggunaan media sempoa menunjukkan bahwa sangat teliti 19,3\%, teliti 77,4\%, cukup teliti 3,3\%, kurang teliti $0 \%$, sangat kurang teliti $0 \%$. Tingkat tanggung jawab dalam penggunaan sempoa menunjukkan bahwa Sangat tanggung jawab 41,9\%, Tanggung jawab 54,8\%, Cukup tanggung jawab 3,3\%, Kurang tanggung jawab $0 \%$ Sangat kurang tanggung jawab $0 \%$. tanggung jawab dalam penggunaan sempoa menunjukkan bahwa Sangat tanggung jawab 41,9\%, Tanggung jawab 54,8\%, Cukup tanggung jawab 3,3\%, Kurang tanggung jawab 0 \% Sangat kurang tanggung jawab $0 \%$.

\section{Daftar Rujukan}

Apriani, A. N., \& Wangid, M. N. (2015). Pengaruh SSP tematik-integratif terhadap karakter disiplin dan tanggung jawab siswa kelas III SD. Jurnal Prima Edukasia, 3(1), 12-25

Ayi dan Safrina. 2015. Peningkatan Kemampuan Berhitumg anak usis 5 - 6 tahun melalui Media

Sempoa di TK Al-Ikhlas Lamhom Kecamatan Lhoknga Aceh Besar. Jurmal Pendidikan Volume 2.

Anugrahana, A. (2019). Pengembangan modul sempoa sebagai alternative dalam mata kuliah inovatif matematika. Journal cendekia: jurnal pendidikan matematika, Vol. 03, No. 2, Agustus 2019, pp. 462-470.

Budiningsih, A. \& M. Syamsul wardani. (2007). Mahir berhitung dengan metode sempoa. Bandung: Sinergi Pustaka Indonesia

Dayanti, Ria W. (2014) pengaruh komunikasi interpersonal, ketelitian (Concientiousness) dan kepuasan kerja terhadap kinerja kepala sekolah paud di medan. Jurnal pendidikan dan kepegawaian, 2(2) (2014).

Dick and Carey. 2013. The Systematic Design of Intruction.

Elly. 2016. Hubungan Kedisiplinan terhadap Hasil Belajar Siswa Kelas V di SD 10 Banda Aceh. Jurnal Pesona Dasar Universitas Syiah Kuala Vol.3 No.4., Oktober 2016 
Endang dkk. 2016. Pengembangan Modul Pembelajaran Matematika dengan Pendekatan Inkuiri untuk membantu siswa SMA Kelas X dalam Memahami Materi Peluang. Jurnal pendidikan Fanrendra Padang. Volume 4 Halaman :140-151 Nomor 1 Maret 2015 E-JUPEKhu (Jurnal Ilmiah Pendidikan Khusus) http://ejournal.unp.ac.id/index.php/jupekhu diunduh tanggal 21 Februari 2019

Nurhayati, N. (2015). Penggunaan Media Animasi Berbasis Visual Basic (Vba) Spreadsheet Excel Untuk Meningkatkan Penguasaan Konsep Mahasiswa Pada Materi Potensial Osilator Harmonik Sederhana. Jurnal Edukasi Matematika dan Sains, 3(1), 54-61.

Lomu, L., \& Widodo, Sri A. (2018). Pengaru motivasi belajar dan disiplin belajar terhadap prestasi belajar matematika siswa. Prosiding Seminar nasional pendidikan matematika etnomatnesia.

Prasasty, Aliffia T. (2017). Pengaruh disiplin dan motivasi belajar terhadap prestasi belajar matematika siswa kelas X SMK Bina Karya Insan Tangerang Selatan. Jurnal ilmiah pendidikan dan ekonomi, Vol. 1, No. 1, Februari 2017, hlm. 65-74.

Putri, Kartika A. (2020). Sistem perancangan aplikasi android beads card sempoa di TC.Genius kids sempoa SIP Tanjung Balai Karimun. Jurnal tikar, Vol. 1, No. 1 (2020).

Ronalis. 2015. Efektivitas Media Sempoa Untuk Meningkatkan Kemampuam Penjumalahan Bilangan Bulat 1-10 untuk Anak Tunagrahita Ringan Kelas II C SLB Rimm, Sylvia. 2003. Mendidik dan Menerapkan Disiplin pada Anakn Prasekolah. Jakarta/; PT Gramedia Putaka Utama.

Rahayu, Ratri. (2016). Peningkatan karakter tanggung jawab siswa SD melalui penilaian produk pada pembelajaran mind mapping. Jurnalkonselinng GUSJIGANG, Vol. 2, No. 1 (2016).

Suyadi, H. S. H. (2012). Meningkatkan Prestasi Belajar Matematika Melalui Metode Kooperatif Model Learning Together Pada Siswa Kelas Viif Smp Negeri 21 Semarang Tahun Pelajaran 2011/2012. Media Penelitian Pendidikan: Jurnal Penelitian dalam Bidang Pendidikan dan Pengajaran, 6(2).

Soviawati, E. (2011). Pendekatan matematika realistik (pmr) untuk meningkatkan kemampuan berfikir siswa di tingkat sekolah dasar. Jurnal Edisi Khusus, 2(2), 79-85.

Susanto. 2013. Teori Belajar dan Pembelajaran di Sekolah Dasar. Jakarta : Prenadamedia Group Suyitno, A. (2004). Dasar-dasar proses pembelajaran. Semarang: UNNES Press.

Siagian, Muhammad D. (206) kemampuan koneksi matematika dalam pembelajaran matematika. Journal of mathematics education and science, Vol. 2, No. 1, Oktober 2016. 
Sumarno, U. (2011). Pembelajaran matematika berbasis karakter. Prosiding seminar nasional pendidikan matematika STKIP Siliwangi Bandung, Vol. 1 (2011).

Syifa, Faiza M. (2015). Penggunaan sempoa dalam pengembangan kemampuan berhitung permulaan anak. Jurnal mahasiswa, Vol. 4, No. 2 (2015).

UU sisdiknas no 20 tahun 2013, https://kelembagaan.ristekdikti.go.id/wpcontent/uploads/2016/08/UU_no_20_th_2003.pdf di downloud tanggal 27 Februari 2020

Yohanes, R. S. (2010). Teori Vygotsky dan implikasinya terhadap pembelajaran matematika. Widya Warta, 2(34), 127-135. 